\title{
Measuring the Sustainable Benefits of Modular and Offsite Construction Delivery Techniques Against Conventional On-Site Construction
}

\author{
Mike BENSON ${ }^{1}$ and Jeff RANKIN ${ }^{2}$ \\ ${ }^{1}$ Master's Candidate, Department of Civil Engineering, University of New Brunswick \\ ${ }^{2}$ Professor and Chair, Department of Civil Engineering, University of New Brunswick \\ ${ }^{*}$ Corresponding author's e-mail: mike.benson@unb.ca
}

\begin{abstract}
It is well known that the use of modular and offsite construction (MOC) techniques for project delivery can yield significant economic, environmental, and social benefits throughout a project's lifetime. Despite these benefits highlighted by the MOC community, there exists a need to objectively measure the sustainable benefits and to integrate them in a comprehensive framework to compare delivery alternatives. The Sustainable Efficiency (SE) model is presented and used to compare the construction of a 2-storey hotel using two delivery methods: i) a conventional onsite construction (COC); and ii) modular and offsite construction (MOC). Sustainable criteria identified in the model originate from ISO's 21929-2 "Framework for sustainability indicator for civil engineering works". These criteria are used to encompass the entire life-cycle of the project, from production and extraction of materials, through construction, operations and maintenance, to the end-of-life or decommissioning stage. MOC presents a significant amount of benefits throughout the entire life-cycle of the project and the SE model presented highlights and takes these benefits into account. Recognizing these benefits can help build the business case for MOC, going past the prescriptive, lowest initial cost, and onsite construction delivery that is widely used in the Canadian construction industry today. Allowing for both the quantitative and qualitative benefits to be included in an objective and metric-based model can address the challenge of making changes to conventional procurement methods, and will strengthen and promote the use of MOC in the construction industry. It was found that, through the use of MOC, the hotel obtained a positive $16.8 \%$ sustainable efficiency score over a conventional stick build method. Significant benefits were a result of reduced greenhouse gas emissions, non-renewable energy use, waste production, and worker health and safety. The single disadvantage determined was the social criteria "Job Creation" where there was a reduced quantity of worker hours required to complete the project.
\end{abstract}

\section{KEYWORDS}

Sustainability, evaluating alternatives, cost-benefit analysis, multi-criteria analysis, life-cycle analysis

\section{INTRODUCTION}

Sustainable development is increasingly becoming a concern for society. This concern can be highlighted from the international to the municipal level. In 2015, the United Nations established a new sustainable development agenda and a historic agreement on climate change and greenhouse gas emissions (United Nations 2015a,b). Regarding civil infrastructure, the Canadian Society for 
Civil Engineers (CSCE) has strengthened its position on sustainable development through its Vision 2020 strategy. One of the three strategic goals identified is to become a 'leader is sustainable infrastructure' (CSCE 2012). These high-level organizations signal to owners (both public and private) that it is important to consider the economic, environmental, and social impacts of construction.

It is well known that the use of modular and offsite construction (MOC) techniques for project delivery can yield significant economic, environmental, and social benefits over the conventional onsite construction (COC). These benefits can include: i) reduced waste; ii) reduced energy use in manufacturing and construction; iii) increased labourer health and safety; iv) reduced construction time; and v) reduced GHG emissions. (Mao et al. 2013; Modular Building Institute n.d.; Rogan et al. 2000).

The goal of this paper is to present an objective-based model to compare and contrast the various advantages and disadvantages of MOC against the COC project delivery. The model comprehensively includes the economic, environmental, and social impacts of each alternative. It accomplishes this by integrating the results of a cost-benefit (CBA) and multi-criteria analysis (MCA) into a single indicator called the Sustainable Efficiency (SE). The model is applied to the construction of a 2-storey hotel in Eastern Canada to demonstrate: i) the SE model's application; and ii) to objectively assess the sustainability benefits of MOC. The model contributes to the development of a tool to allow owners to measure the sustainable impacts of infrastructure and building construction.

\section{METHOD}

To determine the sustainability of any project, there must be a comprehensive and consistent set of criteria under which an evaluation can be based on. For the SE model, the ISO 21929-2 "Framework on the development of sustainability indicators for civil engineering works" is modified and used (ISO 2015).

To evaluate the criteria into a single indicator, a CBA and MCA are used, as represented in (1).

$$
S E_{k}=\sum_{i=1}^{I} w_{i} C B R_{i, k}+\sum_{j=1}^{J} w_{j} V\left(b_{j, k}\right) \quad i=1,2, \ldots I \quad j=1,2, \ldots J
$$

where $S E_{k}=$ sustainable efficiency of project $k, w_{i}$ and $w_{j}=$ the weighting factor for criterion $i$ and $j, C B R_{i, k}=$ cost-benefit ratio of criterion $i$, and $V\left(b_{j, k}\right)=$ the efficiency indicator of criterion $j$.

For comparing project alternatives, the $\mathrm{CBR}_{\mathrm{i}, \mathrm{k}}$ of a criteria is determined by dividing the difference of the present value (PV) social cost of the impact between the two alternatives by the PV of the comparator's social cost. For example, if MOC generates \$10 in GHG emissions, and COC (the comparator) generates $\$ 20$, then the "GHG Emission" efficiency indicator is determined by equation (2).

$$
C B R_{G H G}=\frac{P V\left(G H G_{C}-G H G_{M}\right)}{P V\left(G H G_{C}\right)}=\frac{\$ 20-\$ 10}{\$ 20}=0.5
$$


One of the unique characteristics of the SE model is the use of efficiency-based metrics as indicators for the MCA. These MCA efficiency indicators are expressed in percentages or impact units per dollar of construction. Combined with the cost-benefit ratios determined above, these indicators allow for a simple algebraic addition of results. Integrating CBA and MCA is often a difficult task due to two unique units of measurement (e.g. dollars for the CBA, and a points based system for the MCA). Manipulating the criteria values into ratios (efficiency measures) removes the need to value multi-criteria points with dollar values or vice-versa as attempted with the COSIMA-DSS (Barfod et al. 2011) and other decision support systems.

\section{CASE STUDY: 2-STOREY HOTEL CONSTRUCTION IN EASTERN CANADA}

The sustainable efficiency model is applied to the construction of a new 2-storey hotel in Eastern Canada. The hotel is under construction with the use of modular and prefabricated units from a Canadian company and actual data is used from the construction process, project specifications, and relevant location factors. A hypothetical comparator is generated to simulate if the building were to be built with a COC method. This comparator is used to demonstrate the potential advantages and disadvantages of MOC. The building characteristics (similar for both MOC and COC) are shown in Table 1.

In the case study not all of the criteria listed in ISO 21929-2 are required. Excluded criteria include: i) use of water; ii) eutrophication potential; iii) acidification potential; iv) ozone depletion potential; v) land use changes; vi) ecosystem processes and services; vii) urban sprawl; viii) aesthetic value; ix) cultural heritage; and $x$ ) material use. These exclusions are based on the assumption that the evaluation performed is on the process of construction, and not on the design, and therefore, the excluded criteria will all score equally between MOC and COC. Table 2 summarises the criteria included and their categorisation into either a CBA or MCA.

Table 1. Summary of project characteristics

\begin{tabular}{lcc}
\hline Characteristic & Unit & Value \\
\hline Building Area & $\mathrm{m}^{2}$ & 2880 \\
\# of Stories & & 2 \\
\# of Rooms & & 58 \\
\hline
\end{tabular}

Table 2. Summary of MOC evaluation criteria included in a cost-benefit and multi-criteria analysis

\begin{tabular}{ll}
\hline Cost-Benefit Analysis & Multi-Criteria Analysis \\
\hline Life-Cycle Costs* & Use of Energy \\
Health and Safety & Waste Production \\
Greenhouse Gas Emissions & Job Creation \\
\hline
\end{tabular}

* Excluded in this paper

One of the most significant assumptions in this analysis is that the construction of the foundation and site preparation are identical in both scenarios. The methods which follow are used to determine the quantity and value of each impact on the remaining construction processes. 


\section{Life-Cycle Costs}

The life-cycle of both MOC and COC projects include the same phases: i) design/planning; ii) construction; iii) operations and maintenance; iv) end-of-life or decommissioning. In general, there are examples where individual costs of each approach can be an advantage over the other (e.g., increased upfront design and planning costs of MOC versus COC; increased material costs of MOC versus $\mathrm{COC}$; increased material waste costs of $\mathrm{COC}$ versus $\mathrm{MOC}$; increased labour costs through lower productivity of $\mathrm{COC}$ versus MOC; decreases in decommissioning costs due to reuse opportunities in MOC versus COC). Although a complete analysis of life-cycle costs for both MOC and COC is required for the model, we have chosen to omit it from this paper for length purposes and rather assume that life-cycle costs are equal for both scenarios.

Assumptions: A complete analysis requires details on a COC comparator project and all associated costs for each project phase, revenues generated (e.g., \$/room nights and expected profit margin).

Table 3. Life-cycle costs of MOC and COC

\begin{tabular}{|c|c|c|c|}
\hline \multirow{2}{*}{\multicolumn{4}{|c|}{$\begin{array}{l}\text { Result } \\
\text { Design and Planning Costs }\end{array}$}} \\
\hline & & & \\
\hline \multicolumn{4}{|c|}{ Construction Costs } \\
\hline \multicolumn{4}{|c|}{ Operations and Maintenance Costs } \\
\hline \multicolumn{4}{|c|}{ Decommissioning Costs } \\
\hline \multicolumn{4}{|l|}{ Early Delivery } \\
\hline & Total & $\$ 0$ & $\$ 0$ \\
\hline
\end{tabular}

\section{Health and Safety}

The historical accident frequencies and severities from the appropriate North American Industry Classification System (NAICS) are used to determine the expected health and safety costs of MOC and COC. MOC is assumed to be the Prefabricated Wood Building Manufacturing (NAICS: 321992) industry and COC is assumed to be the Industrial Building and Structure Construction (NAICS: 23621) industry. Combined with the economic value of a statistical life (VSL) of $\$ 8.36$ million, and the corresponding factors for Minor, Moderate, and Severe accidents of 0.002, 0.015, and 0.1875 respectively (US DOT 2011), the expected social cost of an hour of work in each industry can be determined.

Assumptions: No Lost Time, Lost Time, and Severe Claim are equal to Minor, Moderate, and Severe Accident, respectively.

Through the use of Statistics Canada data tables on labour productivity in the residential building construction industry it was determined that, for a COC, a typical building requires 17.8 hours of labour per $\$ 1000$ of building permit value (Statistics Canada 2015a,b). The COC permit value was estimated to be $\$ 4.96$ million using RSMeans (2015). Combined with an industry expert's opinion that the ratio of labour required to complete a MOC project is $70 \%$ of $\mathrm{COC}$, the worker health and safety costs for each project could be determined. 
Table 4. Health and safety costs of MOC and COC industries

\begin{tabular}{lcccc}
\hline & \multicolumn{2}{c}{$\begin{array}{c}\text { Accident Frequency } \\
\text { (accident/FTE) }\end{array}$} & \multicolumn{2}{c}{$\begin{array}{c}\text { Social Cost of Industry } \\
(\$ / \text { wkr-hr) }\end{array}$} \\
Accident Type & MOC & COC & MOC & COC \\
\hline Minor & 0.0444 & 0.0173 & $\$ 0.36$ & $\$ 0.14$ \\
Moderate & 0.0115 & 0.0075 & $\$ 0.72$ & $\$ 0.47$ \\
Severe & 0.0055 & 0.0066 & $\$ 4.16$ & $\$ 4.96$ \\
\cline { 3 - 5 } & & Worker Hours Required & 61824 & $\$ 5.57$ \\
\cline { 3 - 5 } & & Health \& Safety Cost & $\$ 332,810$ & $\$ 58325$ \\
\hline
\end{tabular}

\section{GHG Emissions}

Mao et al. (2013) has shown previously that MOC can have reduced GHG emissions in the construction of high-rise of apartments. The calculation boundary assumed for this analysis is consistent with the previous analysis and is shown in Figure 1.

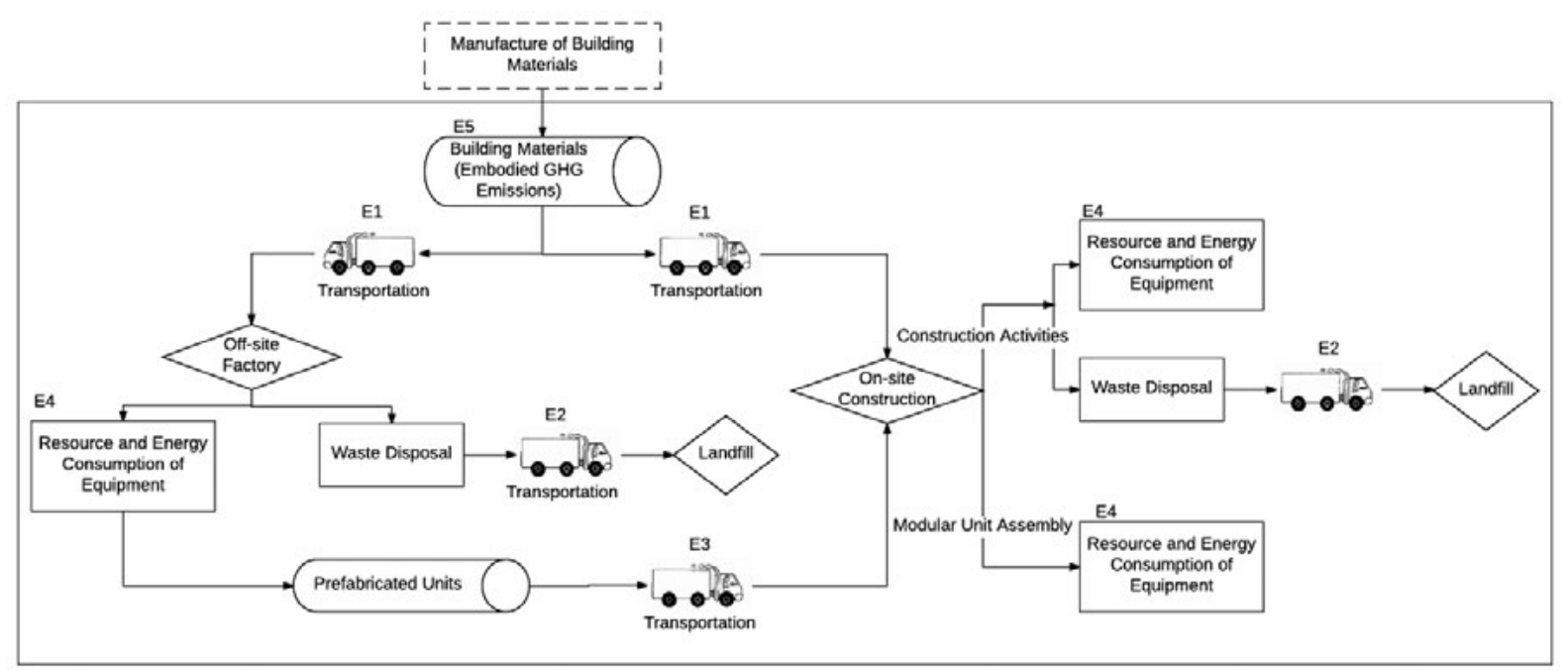

Figure 1. Calculation boundaries for GHG emissions and energy consumption (recreated from Mao et al. 2013)

Using emission factors for the transportation methods (US EPA 2016), electricity grid (NB Power 2010), and construction equipment (US EPA 2010), the total quantity of GHG emissions for each approach can be determined. Monetizing the impact is done by multiplying the quantity of GHG emissions by the social cost of GHG emissions of $\$ 42.9$ per ton (ECC Canada 2016). GHG Emission results can be found in Table 5. Excluded in this analysis are the GHG emissions due to the embodied energy of building materials. This is due to a lack of certainty of the materials required for construction of either approach.

Assumptions: Local electricity grid emission factors are applicable to the construction of the apartment building. Various equipment sizes and runtimes. Quantity of laborer travel to and from site. 
Table 5. Summary of GHG emission costs

\begin{tabular}{llc}
\hline Result & MOC & COC \\
\hline Quantity (ton) & 141.5 & 209.9 \\
Social Cost & $\$ 6,070$ & $\$ 9,007$ \\
\hline
\end{tabular}

\section{Multi-Criteria Analysis}

Included in the multi-criteria analysis are the following criteria: i) energy use; ii) waste produced; and iii) job creation. Each of the criteria is assigned a relevant efficiency indicator which is used to determine how efficiently the project alternative meets the goals and objectives of the criterion. Additionally, a point scale is determined to evaluate each criterion. All criteria are evaluated on a -1 to +1 point scale as shown in the example for the "Waste Production" criteria in Table 6 .

Table 6. Waste Production point scale

\begin{tabular}{|c|c|c|c|c|c|c|c|c|c|c|}
\hline Criteria & Indicator & & & & & $\mathrm{CO}$ & & & & \\
\hline $\begin{array}{l}\text { Waste } \\
\text { Production }\end{array}$ & $=\frac{\left(W P_{C}-W P_{M}\right)}{W P_{C}}$ & -1.0 & -0.75 & -0.5 & -0.25 & 0 & 0.25 & 0.5 & 0.75 & 1.0 \\
\hline
\end{tabular}

where $\mathrm{WP}_{\mathrm{C}}$ is the quantity of waste produced in a $\mathrm{COC}$ and $\mathrm{WP}_{\mathrm{M}}$ is the quantity of waste produced in a MOC.

\section{Results and Discussion}

Table 7 summarizes the results of the analysis and Table 8 summarizes the evaluation of the MOC and COC delivery options using the Sustainable Efficiency model.

Table 7. Analysis results summary

\begin{tabular}{|c|c|c|c|}
\hline \multirow{2}{*}{ Result } & \multicolumn{2}{|c|}{ Value } & \multirow{2}{*}{ Unit } \\
\hline & MOC & $\mathrm{COC}$ & \\
\hline GHG Emissions & 141.5 & 209.9 & Tons $\mathrm{CO}_{2} \mathrm{e}$ \\
\hline & $\$ 6,070$ & $\$ 9,007$ & Social Cost \\
\hline Worker Health and Safety & $\$ 332,811$ & $\$ 506,024$ & Social Cost \\
\hline Waste Produced & 1202 & 1848 & Tons \\
\hline Non-Renewable Energy Use & 2738785 & 3844475 & MJ \\
\hline Worker Hours & 61828 & 88326 & Hours \\
\hline
\end{tabular}

Table 8. Summary of weighted results.

\begin{tabular}{lclcc}
\hline Criteria & Wt. & Indicator & Score & $\begin{array}{c}\text { Wt. Score } \mathrm{x} \\
100\end{array}$ \\
\hline Life-Cycle Costs & $16.7 \%$ & $={ }^{P V}\left(L C C_{C}-L C C_{M}\right) / P V\left(L C C_{C}\right)$ & 0.00 & 0.00 \\
GHG Emissions & $16.7 \%={ }^{2}\left(G H G_{C}-G H G_{M}\right) / P V\left(G H G_{C}\right)$ & 0.33 & 5.43 \\
Worker Health and Safety & $16.7 \%$ & $=P V\left(H \& S_{C}-H \& S_{M}\right) / P V\left(H \& S_{C}\right)$ & 0.34 & 5.71 \\
\hline
\end{tabular}




$\begin{array}{lrrr}\text { Waste Production } & 16.7 \%=\left(W P_{C}-W P_{M}\right) /\left(W P_{C}\right) & 0.35 & 5.83 \\ \text { Energy Use } & 16.7 \%=\left(E U_{C}-E U_{M}\right) /\left(E U_{C}\right) & 0.29 & 4.79 \\ \text { Job Creation } & 16.7 \%=\left(J C_{C}-J C_{M}\right) /\left(J C_{C}\right) & -0.30 & -5.00 \\ & & & \end{array}$

From these results it is evident that the use of modular and off-site construction can have significant economic, environmental, social benefits. The Sustainable Efficiency model demonstrate that using MOC for this particular project generates a positive $16.8 \%$ sustainable efficiency benefit (again, without the expected increase in benefits due to life cycle costs for a MOC approach). The MOC project uses significant less energy, generated much less waste, and is a much safer form of construction. The single disadvantage of MOC was the reduced quantity of labour required. From a social perspective, this can reduce the number of jobs available to citizens in an area.

For the case study analysis, each criterion was given an identical weight of 0.167 . Ideally, a decision-maker will use a standardised and objective-based method to determine appropriate weighting factors for each criterion. This flexibility allows for the SE model to be adjusted appropriate depending on the decision maker's preferences. It should be noted that varying the weighting factors of some criteria can have a significant impact on the final result. This variability, along with the potential for uncertainty, is shown in the sensitivity analysis in Figure 2.

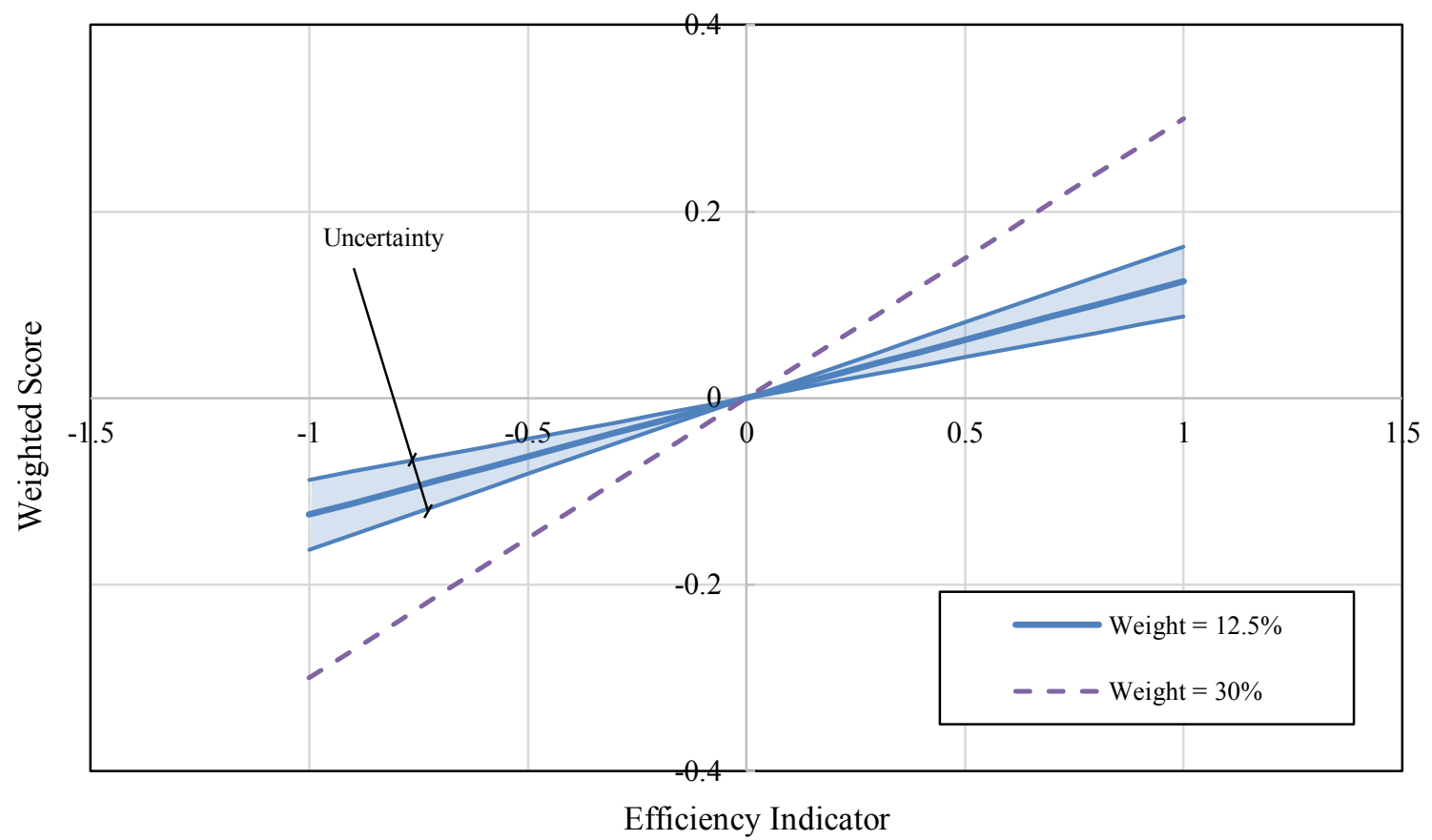

Figure 2. Theoretical sensitivity analysis of an efficiency indicator and the impact on weighted score from weighting factors and uncertainty 


\section{CONCLUSION}

The Sustainable Efficiency model is presented as a potential metric-based tool to measure, compare, and contrast the sustainable benefits of modular and offsite construction. By integrating all of the economic, environmental, and social advantages and disadvantages into a single indicator, decision makers can now get a better understanding of the overall sustainability impact. Additionally, the model is flexible enough to all for decision makers to adjust the weighting factors to prioritize certain goals over others.

Research is on-going to support a more detailed evaluation. This detailed evaluation will determine more accurate and realistic results. The primary purpose of this paper is not to demonstrate results with little uncertainty, but to demonstrate the use of a model to evaluate the sustainable impacts of infrastructure projects and its application for the modular and offsite construction industry. A more complete analysis will account for the uncertainty of the variables and will provide a range of possible outcomes. The authors acknowledge the support of members of the MOC industry for their help in providing a case study scenario.

\section{REFERENCES}

Barfod, M. B., Salling, K. B., and Leleur, S. (2011). "Composite decision support by combining cost-benefit and multi-criteria decision analysis." Decision Support Systems, Elsevier B.V., 51(1), 167-175.

CSCE. (2012). “CSCE's Vision 2020.” <https://csce.ca/custom-content/uploads/2012/03/Vision2020-member-information-August-10-12-jak2.pdf?ef655a>.

ECC Canada. (2016). "Technical Update to Environment and Climate Change Canada's Social Cost of Greenhouse Gas Estimates." <http://ec.gc.ca/cc/default.asp?lang=En\&n=BE7057791\#SCC-Sec3> (Jul. 7, 2016).

ISO. (2015). ISO/TS 21929-2 Sustainability in building construction - sustainability indicators Part 2: Framework for the development of indicators for civil engineering works. Geneva.

Mao, C., Shen, Q., Shen, L., and Tang, L. (2013). "Comparative study of greenhouse gas emissions between off-site prefabrication and conventional construction methods: Two case studies of residential projects." Energy and Buildings, 66, 165-176.

Modular Building Institute. (n.d.). "Why Building Modular?" 2016, $<$ http://www.modular.org/HtmlPage.aspx?name=why_modular $>$ (Jul. 7, 2016).

NB Power. (2010). NB Power Strategic Plan.

Rogan, A. L., Lawson, R. M., and Bates-Brkljac, N. (2000). "Value and Benefits Assessment of Modular Construction." Steel Construction Institute.

RSMeans. (2015). 2015 Building Construction Cost Data Book. RSMeans.

United Nations. (2015a). Adoption of the Paris Agreement. FCCC/CP/2015/L.9/Rev.1.

United Nations (2015b). Draft outcome document of the United Nations summit for the adoption of the post-2015 development agenda. A/69/L.85.

US DOT. (2011). Treatment of the Economic V alue of a Statistical Life in Departmental Analyses - 2011 Interim Adjustment.

US EPA. (2010). "Exhaust and Crankcase Emission Factors for Nonroad Engine Modeling Compression-Ignition." EPA-420-R-10-018. NR-009d. U.S. Environmental Protection Agency, 1-141.

US EPA. (2016). “Greenhouse Gas Inventory Guidance: Direct Emissions from Mobile Combustion Sources." 